\title{
(2) OPEN ACCESS \\ Utilisation of pharmacy-based sexual and reproductive health services: a quantitative retrospective study
}

\author{
Julia Gauly (D) , ${ }^{1}$ Helen Atherton, ${ }^{1}$ Peter K Kimani, ${ }^{1}$ Jonathan Ross ${ }^{2}$
}

${ }^{1}$ Warwick Medical School, University of Warwick, Coventry, UK

${ }^{2}$ Whittall Street Clinic, University Hospital Birmingham, Birmingham, UK

\section{Correspondence to} Julia Gauly, Warwick Medical School, University of Warwick, Coventry, UK; J.Gauly@warwick. ac.uk

Received 20 February 2020 Revised 17 June 2020 Accepted 27 June 2020 Published Online First 15 August 2020

\section{Check for updates}

(c) Author(s) (or their employer(s)) 2021. Re-use permitted under CC BY-NC. No commercial re-use. See rights and permissions. Published by BMJ.

To cite: Gauly J,

Atherton $\mathrm{H}$, Kimani PK,

et al. Sex Transm Infect

2021;97:126-133.
ABSTRACT

Objectives To explore the utilisation of pharmacybased sexual and reproductive health services (SRHS) in order to optimise delivery and identify barriers to access. Methods The health provider Umbrella offers six SRHS from over 120 pharmacies in Birmingham (England). In this retrospective study, data collected between August 2015 and August 2018 were used to analyse uptake, user characteristics and attendance patterns according to day of the week.

Results A total of 60498 requests for a pharmacy service were included in the analysis. Emergency contraception (50.4\%), condoms (33.1\%) and STI selfsampling kits (9.6\%) accounted for more than $90 \%$ of all requests. A lower uptake of services was observed for the contraceptive injection $(0.6 \%)$, oral contraception (5.4\%) and chlamydia treatment (1.0\%). Services were most likely to be requested by those self-identifying as female (85.6\%), and those aged 16-24 years (53.8\%). Based on available ethnicity data $(n=54668)$, most requests for a service were made by White/White British individuals (43.4\%) and Asian/Asian British people (23.1\%). The largest number of services were delivered on Mondays $(20.9 \%)$ and the lowest on Sundays (5.0\%). A high proportion of requests for services on Saturdays (57.0\%), Sundays (67.6\%) and Mondays (54.4\%) were made by females presenting for emergency contraception. Conclusion The evaluation of healthcare utilisation is important to help refine and optimise the delivery of services. However, information relating to pharmacybased SRHS is scarce and often limited to a single type of service provision. Overall, a wide range of pharmacybased services were accessed by a diverse range of people, suggesting that pharmacies are a suitable provider of many SRHS. However, the routinely collected data analysed in the study had several limitations restricting the analysis. Sexual health providers should ensure they collect data which are as comprehensive as is possible in order to help understand the utilisation of services.

\section{INTRODUCTION}

Cuts to National Health Service (NHS) sexual health budgets have led to the development of new service delivery pathways. Several countries including Australia, Canada, New Zealand and the USA have increasingly started to expand the use of pharmacies for healthcare delivery and the NHS in the UK has been at the forefront of expanding the role of pharmacy staff and services. ${ }^{1}$ While pharmacies in England have been providing limited sexual and reproductive health services (SRHS) for several years, ${ }^{2}$ primarily emergency contraception and chlamydia screening, they are now increasingly offering a wider variety of options, including the provision of: condoms, oral contraception, the contraceptive injection and screening/treatment for STIs. ${ }^{3}$ When provided via an NHS sexual health provider, these services are all free of charge to the user.

It is important to evaluate the utilisation of healthcare services to optimise delivery and identify barriers to access. ${ }^{4}$ However, to date, evidence on the utilisation of pharmacy-based SRHS is scarce and limited to single sexual health conditions or needs such as chlamydia screening and oral contraception. ${ }^{56}$ This study is the first to analyse the utilisation of a large range of pharmacy-based SRHS using data collected over 3 years in Birmingham (England).

Our objectives were

- To describe the uptake of six SRHS encompassing contraception, and testing and treatment for STIs.

- To describe the characteristics of those using pharmacy-based SRHS.

- To describe the attendance patterns of individuals using pharmacy-based SRHS.

\section{METHODS}

Umbrella and their pharmacy-based SRHS

In August 2015, the sexual health provider in Birmingham (Umbrella) ${ }^{7}$ started to offer services through many community pharmacies. The services are funded by Birmingham's local council and are free of charge to the user. Pharmacies which would like to provide Umbrella's services have to fulfil certain criteria including having a private consultation room. Overall, between August 2015 and August 2018, the number of community pharmacies in Birmingham (England) has decreased from 301 to $285 .{ }^{8}$ Umbrella pharmacies can operate either at the 'Tier 1' level or the more comprehensive 'Tier 2' level. Between August 2015 and August 2018, the number of pharmacies offering more extensive Umbrella 'Tier 2' services increased from 18 to 47 , whereas the number of 'Tier 1' pharmacies decreased from 158 to 80 . Hence, the total number of Umbrella pharmacies delivering SRHS decreased from 176 pharmacies to 127 between August 2015 
and August 2018. Pharmacies which decide to deliver the 'Tier 2' level have to undergo more comprehensive pharmacy staff training compared with 'Tier 1' pharmacies. Training for both 'Tier 1' and 'Tier 2' services is delivered by Umbrella's education team.

Both 'Tier 1' and 'Tier 2' pharmacies provide condoms, emergency contraception and STI self-sampling kits testing for chlamydia and gonorrhoea from available stock, which is dispensed directly to pharmacy users. While 'Tier 1' pharmacies can only provide women presenting for emergency contraception with one emergency contraceptive pill, 'Tier 2' pharmacies can provide women with two emergency contraceptive pills, one for immediate and one for future use (Advance EC). 'Tier 2' pharmacies also provide the contraceptive injection, oral contraception, chlamydia treatment and comprehensive STI self-sampling kits (testing for chlamydia, gonorrhoea, syphilis and HIV, plus hepatitis B for men who have sex with men) from in store stock provided directly to pharmacy users. 'Tier 1' pharmacies do not have those comprehensive STI self-sampling kits in stock. However, comprehensive STI self-sampling kit can be preordered on the Umbrella website and be collected at an Umbrella pharmacy of their choice ('Tier 1' or 'Tier 2' pharmacy). The comprehensive STI self-sampling kits are the only service that can be pre-ordered on the Umbrella website.

An overview of Umbrella's pharmacy services and eligibility criteria is provided in table 1 .

\section{Study design}

A retrospective analysis was performed to evaluate all SRHS requests made by users at Umbrella pharmacies between August 2015 and August 2018.

\section{Data collection}

Data were available from two data sources: pharmacy electronic patient records (PharmOutcomes) and online patient questionnaires (collected via the Umbrella website).

When people attended for emergency contraception, oral contraception, contraceptive injection, condoms or chlamydia treatment, they were seen in a consultation room by pharmacy staff, who recorded demographic and clinical information on an electronic patient record (PharmOutcomes). Those who wanted to pre-order an STI self-sampling kit via the Umbrella website had to complete an online questionnaire and then collect the STI self-sampling kit from an Umbrella pharmacy of their choice

Table 1 Overview of Umbrella's pharmacy services, eligibility criteria, data source and characteristics analysed for this study

\begin{tabular}{|c|c|c|c|c|c|}
\hline SRHS provided & Pharmacy 'tier' & Eligibility by gender & Eligibility by age & Data source & $\begin{array}{l}\text { Associated data included in } \\
\text { this analysis }\end{array}$ \\
\hline Emergency Contraception & Tier 1 and Tier 2 & Females & $13-60$ & $\begin{array}{l}\text { Pharmacy Electronic Patient Record } \\
\text { (PharmOutcomes) }\end{array}$ & $\begin{array}{l}\text { Age } \\
\text { Gender } \\
\text { Ethnicity } \\
\text { Weekday of attendance }\end{array}$ \\
\hline $\begin{array}{l}\text { Advance Emergency } \\
\text { Contraception }\end{array}$ & Tier 2 & Females & $13-60$ & $\begin{array}{l}\text { Pharmacy Electronic Patient Record } \\
\text { (PharmOutcomes) }\end{array}$ & $\begin{array}{l}\text { Age } \\
\text { Gender } \\
\text { Ethnicity } \\
\text { Weekday of attendance }\end{array}$ \\
\hline $\begin{array}{l}\text { Referral or Appointment for the } \\
\text { copper coil at closest sexual } \\
\text { health clinic }\end{array}$ & Tier 1 and Tier 2 & Females & $13-60$ & $\begin{array}{l}\text { Pharmacy Electronic Patient Record } \\
\text { (PharmOutcomes) }\end{array}$ & $\begin{array}{l}\text { Age } \\
\text { Gender } \\
\text { Ethnicity } \\
\text { Weekday of attendance }\end{array}$ \\
\hline Oral Contraception & Tier 2 & Females & $13-60$ & $\begin{array}{l}\text { Pharmacy Electronic Patient Record } \\
\text { (PharmOutcomes) }\end{array}$ & $\begin{array}{l}\text { Age } \\
\text { Gender } \\
\text { Ethnicity } \\
\text { Weekday of attendance }\end{array}$ \\
\hline Contraceptive Injection & Tier 2 & Females & $13-60$ & $\begin{array}{l}\text { Pharmacy Electronic Patient Record } \\
\text { (PharmOutcomes) }\end{array}$ & $\begin{array}{l}\text { Age } \\
\text { Gender } \\
\text { Ethnicity } \\
\text { Weekday of attendance }\end{array}$ \\
\hline Condoms & Tier 1 and Tier 2 & Females and males & $\geq 13$ & $\begin{array}{l}\text { Pharmacy Electronic Patient Record } \\
\text { (PharmOutcomes) }\end{array}$ & $\begin{array}{l}\text { Age } \\
\text { Gender } \\
\text { Ethnicity } \\
\text { Weekday of attendance }\end{array}$ \\
\hline $\begin{array}{l}\text { Collection of pre-ordered STI } \\
\text { self-sampling kits testing for up } \\
\text { to five STIs }\end{array}$ & Tier 1 and Tier 2 & Females and males & $\geq 16$ & Online Patient Questionnaire (Umbrella website) & $\begin{array}{l}\text { Age } \\
\text { Gender } \\
\text { Weekday of attendance }\end{array}$ \\
\hline $\begin{array}{l}\text { STI self-sampling kits testing for } \\
\text { up to five STIs }\end{array}$ & Tier 2 & Females and males & $\geq 16$ & $\begin{array}{l}\text { Pharmacy Electronic Patient Record } \\
\text { (PharmOutcomes) } \\
\text { Until } 6 \text { Feb } 2018 \text { and Pharmacy Online Patient } \\
\text { Questionnaire (Umbrella website) from } 7 \text { Feb } \\
2018 \text { onwards }\end{array}$ & $\begin{array}{l}\text { Age } \\
\text { Gender } \\
\text { Weekday of attendance }\end{array}$ \\
\hline $\begin{array}{l}\text { Chlamydia and Gonorrhoea STI } \\
\text { self-sampling kit supplied to } \\
\text { women presenting for emergency } \\
\text { contraception }\end{array}$ & Tier 1 and Tier 2 & Females & $15-24$ & $\begin{array}{l}\text { Pharmacy Electronic Patient Record } \\
\text { (PharmOutcomes) } \\
\text { until } 6 \text { Feb } 2018 \text { and Online Patient } \\
\text { Questionnaire (Umbrella Website) from } 7 \text { Feb } \\
2018 \text { onwards }\end{array}$ & $\begin{array}{l}\text { Age } \\
\text { Gender } \\
\text { Weekday of attendance }\end{array}$ \\
\hline Chlamydia Treatment & Tier 2 & Females and males & $\geq 13$ & $\begin{array}{l}\text { Pharmacy Electronic Patient Record } \\
\text { (PharmOutcomes) }\end{array}$ & $\begin{array}{l}\text { Age } \\
\text { Gender } \\
\text { Ethnicity } \\
\text { Weekday of attendance }\end{array}$ \\
\hline
\end{tabular}


('Tier 1' or 'Tier 2' pharmacy). Data from individuals who were provided with an STI kit from a pharmacy without pre-ordering were collected in PharmOutcomes before 6 February 2018, and via the Umbrella website thereafter.

Each user of an Umbrella pharmacy service was automatically assigned a Patient Identification Number (ID). If a user returned to the same pharmacy to use the Umbrella service again, this was registered under the original patient ID. However, if a pharmacy user subsequently visited a different Umbrella pharmacy, this was recorded under a new patient ID. Hence, since users could have been recorded under different patient IDs it was not possible to evaluate frequency of attendance for individual patients.

If a pharmacy user used more than one of the 'Tier 1' or 'Tier 2 ' services (eg, emergency contraception and condoms), this was recorded as separate requests. It was therefore not possible to evaluate whether multiple services were delivered at a single attendance or over several pharmacy visits.

Service users self-assigned their demographic information: ethnicity, age and gender. When asked for their gender, users had the possibility to self-identify as female, male or transgender. Ethnicity data were collected consistently for all services except the STI self-sampling kits. Inconsistencies in the data collection meant that it was not possible to analyse ethnicity data on STI self-sampling kits, specifically no ethnicity data were collected until March 2017 and subsequently different ethnic group categories were used. Ethnicity data were therefore only analysed for individuals accessing emergency contraception, oral contraception, contraceptive injection, condoms and chlamydia treatment.

User activity recorded on PharmOutcomes and the STI website were combined into a single data set and re-coded where necessary. The data set included:

- PharmOutcomes data on all user requests recorded for emergency contraception, oral contraception, contraceptive injection, chlamydia treatment, condoms between August 2015 and August 2018.

- PharmOutcomes data (recorded between August 2015 and the sixth February 2018) and STI Website data (recorded between 7 February 2018 and August 2018) on all STI selfsampling kits that were provided directly to users

- STI Website data on all STI self-sampling kits that were ordered online and collected from a pharmacy between August 2015 and August 2018

An overview of the data sources and the characteristics analysed by SRHS is presented in table 1 .

\section{Inclusion criteria}

Only those service records which met Umbrella's eligibility criteria outlined in table 1 were included in the analysis.

\section{Data analysis}

A descriptive analysis, count and percentage for categorical characteristics and range and median (IQR) for continuous characteristics, was conducted using IBM SPSS V.24 to evaluate:

- Uptake: the total number of requests for each SRHS.

- User characteristics: age, gender and ethnicity; age distribution by gender; ethnicity distribution by gender.

- Attendance pattern: the number of services provided by the pharmacy according to the day of the week and type of SRHS. For those users who pre-ordered an STI kit online, the weekday that the kit was collected rather than preordered was analysed.

\section{RESULTS}

In total, 60498 data entries were included in the analysis. An overview of the service uptake, service user demographics and attendance patterns by the day of the week is provided in table 2 . Information on the age-distribution, ethnicity-distribution and weekday of service received by gender can be found in table 3 .

\section{Service use}

Emergency Contraception (50.4\%), condoms (33.1\%) and STI self-sampling kits $(9.6 \%)$ accounted for more than $90 \%$ of all service requests. The contraceptive injection was least frequently requested $(0.6 \%)$, with oral contraception $(5.4 \%)$ and chlamydia treatment $(1.0 \%)$ also being used at relatively low levels.

\section{Demographic characteristics}

\section{Gender}

For the services available to all sexes, people recorded as female accounted for the majority of requests: condoms (females: $66.4 \%$ vs males: $33.1 \%$ ), STI self-sampling kits (females: $69.4 \%$ vs males: $30.5 \%$ ) and chlamydia treatment (females: $64.6 \%$ vs males: $34.9 \%)$. Fifteen people recorded as transgender used the service over the 3 -year study period $(<1 \%)$.

\section{Age}

People in the age group 16 to 24 years accounted for more than $50 \%$ of all requests. For all services consistently, females and males 16-24years old accounted for the largest number of service requests. The median age across all services was 24 years (IQR 20-30). The median age was lowest for users who requested an STI kit (21 years old (IQR 20-27)) and highest for EC (25 years old (IQR 20-29)).

\section{Ethnicity}

As mentioned in the methods section, ethnicity data were not available for pharmacy users who requested an STI self-sampling kit $(n=5830 / 60498)$ due to inconsistencies in the data collection.

Based on data on the remaining 54668 service requests, White/White British individuals were the largest group who accessed pharmacy services (43.3\%), followed by Asian/Asian British (23.1\%), Black/Black British (15.1\%), mixed (6.4\%) and other ethnic groups $(2.0 \%)$.

\section{Attendance patterns by day of week}

All services except the contraceptive injection and chlamydia treatment were most frequently accessed on Monday, which was the most common day to present in a pharmacy for a SRHS overall (20.9\%). The uptake of services on a Saturday (12.2\%) and Sunday $(5.0 \%)$ was lower. The majority of requests on Saturday (57.0\%), Sunday (67.6\%) and Monday (54.4\%) were made by women presenting for emergency contraception. Females were most likely to request emergency contraceptive, condoms and STI self-sampling kits on Mondays, and chlamydia treatment and the contraceptive injection on Wednesday. In contrast, males were most likely to obtain condoms and chlamydia treatment on Fridays and STI self-sampling kits on Tuesdays.

\section{DISCUSSION}

\section{Summary of the main findings}

A large number of requests for sexual health related care delivered via pharmacies were made over a 3-year period. As might be expected, there was a higher level of provision for certain services (emergency contraception, condoms, STI self-sampling kits), which were available in all Umbrella pharmacies (between 


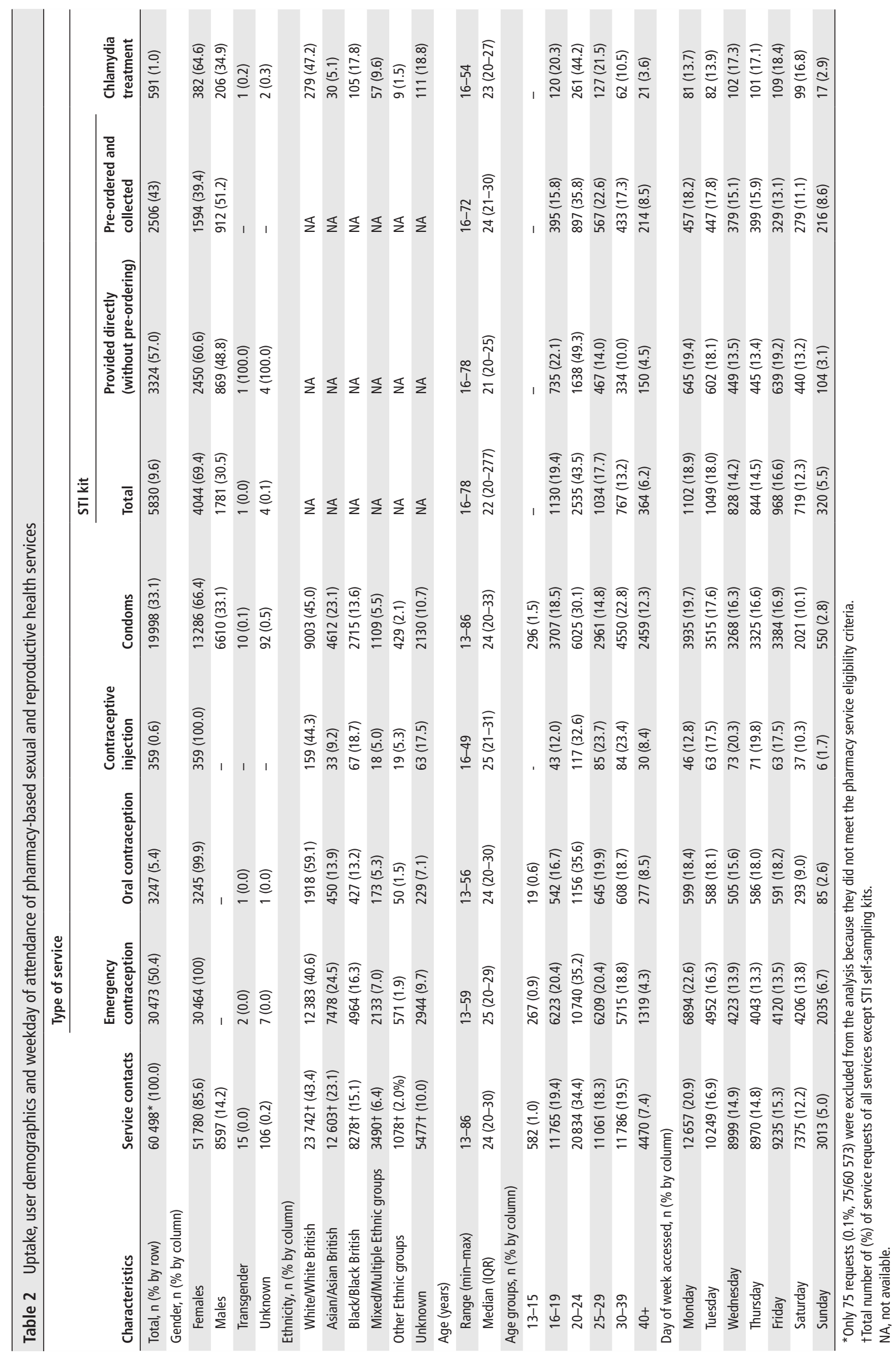


Table 3 Distribution of age, ethnicity and weekday accessed by gender

\begin{tabular}{|c|c|c|c|c|c|c|c|}
\hline Gender & Service & Age group & Frequency (\%) & Ethnicity & Frequency (\%) & Weekday of attendance & Frequency (\%) \\
\hline \multirow[t]{42}{*}{ Females } & \multirow{7}{*}{$\begin{array}{l}\text { Emergency contraception } \\
(\mathrm{n}=30464)\end{array}$} & $13-15$ & $267(0.9)$ & White/White British & $12380(40.6)$ & Monday & $6893(22.6)$ \\
\hline & & $16-19$ & $6223(20.4)$ & Asian/Asian British & $7475(24.5)$ & Tuesday & $4951(16.3)$ \\
\hline & & $20-24$ & $10734(35.2)$ & Black/Black British & $4964(16.3)$ & Wednesday & $4223(13.9)$ \\
\hline & & $25-29$ & $6208(20.4)$ & Mixed/Multiple ethnic groups & $2133(7.0)$ & Thursday & $4040(13.3)$ \\
\hline & & $30-39$ & $5713(18.8)$ & Other ethnic groups & $571(1.9)$ & Friday & $4119(13.5)$ \\
\hline & & $40+$ & $1319(4.3)$ & Unknown & $2941(9.7)$ & Saturday & $4203(13.8)$ \\
\hline & & & & & & Sunday & $2035(6.7)$ \\
\hline & \multirow{7}{*}{$\begin{array}{l}\text { Oral contraception } \\
(n=3245)\end{array}$} & $13-15$ & $19(0.6)$ & White/White British & $1917(59.1)$ & Monday & $599(18.5)$ \\
\hline & & $16-19$ & $541(16.7)$ & Asian/Asian British & $449(13.8)$ & Tuesday & $587(18.1)$ \\
\hline & & $20-24$ & $1156(35.6)$ & Black/Black British & $427(13.2)$ & Wednesday & $505(15.6)$ \\
\hline & & $25-29$ & $644(19.8)$ & Mixed/Multiple ethnic groups & $173(5.3)$ & Thursday & $585(18.0)$ \\
\hline & & $30-39$ & $608(18.7)$ & Other ethnic groups & $50(1.5)$ & Friday & $591(18.2)$ \\
\hline & & $40+$ & $277(8.5)$ & Unknown & $229(7.1)$ & Saturday & $293(9.0)$ \\
\hline & & & & & & Sunday & $85(2.6)$ \\
\hline & \multirow{7}{*}{$\begin{array}{l}\text { Contraceptive injection } \\
(\mathrm{n}=359)\end{array}$} & $13-15$ & - & White/White British & $159(44.3)$ & Monday & $46(12.8)$ \\
\hline & & $16-19$ & $43(12.0)$ & Asian/Asian British & $33(9.2)$ & Tuesday & $63(17.5)$ \\
\hline & & $20-24$ & $117(32.6)$ & Black/Black British & $67(18.7)$ & Wednesday & $73(20.3)$ \\
\hline & & $25-29$ & $85(23.7)$ & Mixed/Multiple ethnic groups & $18(5.0)$ & Thursday & $71(19.8)$ \\
\hline & & $30-39$ & $84(23.4)$ & Other ethnic groups & $19(5.3)$ & Friday & $63(17.5)$ \\
\hline & & $40+$ & $30(8.4)$ & Unknown & $63(17.5)$ & Saturday & $37(10.3)$ \\
\hline & & & & & & Sunday & $6(1.7)$ \\
\hline & \multirow[t]{7}{*}{ Condoms ( $n=13286$ ) } & $13-15$ & $109(0.8)$ & White/White British & $6425(48.4)$ & Monday & $2777(20.9)$ \\
\hline & & $16-19$ & $2427(18.3)$ & Asian/Asian British & $2923(22.0)$ & Tuesday & $2343(17.6)$ \\
\hline & & $20-24$ & 4370 (32.9) & Black/Black British & $1755(13.2)$ & Wednesday & $2145(16.1)$ \\
\hline & & $25-29$ & $2227(16.8)$ & Mixed/Multiple ethnic groups & $825(6.2)$ & Thursday & $2122(16.0)$ \\
\hline & & $30-39$ & $3132(23.6)$ & Other ethnic groups & $217(1.6)$ & Friday & $2083(15.7)$ \\
\hline & & $40+$ & $1021(7.7)$ & Unknown & $1141(8.6)$ & Saturday & $1435(10.8)$ \\
\hline & & & & & & Sunday & $381(2.9)$ \\
\hline & \multirow{7}{*}{$\begin{array}{l}\text { STI self-sampling kits } \\
(n=4044)\end{array}$} & $13-15$ & - & White/White British & NA & Monday & $779(19.3)$ \\
\hline & & $16-19$ & $886(21.9)$ & Asian/Asian British & NA & Tuesday & $699(17.3)$ \\
\hline & & $20-24$ & $1847(45.7)$ & Black/Black British & NA & Wednesday & $559(13.8)$ \\
\hline & & $25-29$ & $656(16.2)$ & Mixed/Multiple ethnic groups & NA & Thursday & $578(14.3)$ \\
\hline & & $30-39$ & $480(11.9)$ & Other ethnic groups & NA & Friday & $693(17.1)$ \\
\hline & & $40+$ & $175(4.3)$ & Unknown & NA & Saturday & $513(12.7)$ \\
\hline & & & & & & Sunday & $223(5.5)$ \\
\hline & \multirow{7}{*}{$\begin{array}{l}\text { Chlamydia treatment } \\
(\mathrm{n}=382)\end{array}$} & $13-15$ & - & White/White British & $203(53.1)$ & Monday & $56(14.7)$ \\
\hline & & $16-19$ & $96(25.1)$ & Asian/Asian British & $13(3.4)$ & Tuesday & $52(13.6)$ \\
\hline & & $20-24$ & $179(46.9)$ & Black/Black British & $63(16.5)$ & Wednesday & $71(18.6)$ \\
\hline & & $25-29$ & $73(19.1)$ & Mixed/Multiple ethnic groups & $39(10.2)$ & Thursday & $69(18.1)$ \\
\hline & & $30-39$ & $27(7.1)$ & Other ethnic groups & $5(1.3)$ & Friday & $68(17.8)$ \\
\hline & & $40+$ & $7(1.8)$ & Unknown & $59(15.4)$ & Saturday & $57(14.9)$ \\
\hline & & & & & & Sunday & $9(2.4)$ \\
\hline \multirow[t]{14}{*}{ Males } & \multirow[t]{7}{*}{ Condoms $(n=6610)$} & $13-15$ & $187(2.8)$ & White/White British & $2550(38.6)$ & Monday & $1146(17.3)$ \\
\hline & & $16-19$ & $1261(19.1)$ & Asian/Asian British & $1670(25.3)$ & Tuesday & $1153(17.4)$ \\
\hline & & $20-24$ & $1630(24.7)$ & Black/Black British & $951(14.4)$ & Wednesday & $1102(16.7)$ \\
\hline & & $25-29$ & $730(11.0)$ & Mixed/Multiple ethnic groups & $283(4.3)$ & Thursday & $1189(18.0)$ \\
\hline & & $30-39$ & $1373(20.8)$ & Other ethnic groups & $211(3.2)$ & Friday & $1277(19.3)$ \\
\hline & & $40+$ & $1429(21.6)$ & Unknown & $945(14.3)$ & Saturday & $577(8.7)$ \\
\hline & & & & & & Sunday & $166(2.5)$ \\
\hline & \multirow{7}{*}{$\begin{array}{l}\text { STI self-sampling kits } \\
(n=1781)\end{array}$} & $13-15$ & - & White/White British & NA & Monday & $323(18.1)$ \\
\hline & & $16-19$ & $243(13.6)$ & Asian/Asian British & NA & Tuesday & $348(19.5)$ \\
\hline & & $20-24$ & $686(38.5)$ & Black/Black British & NA & Wednesday & $268(15.0)$ \\
\hline & & $25-29$ & $378(21.2)$ & Mixed/Multiple ethnic groups & NA & Thursday & $266(14.9)$ \\
\hline & & $30-39$ & $285(16.0)$ & Other ethnic groups & NA & Friday & $274(15.4)$ \\
\hline & & $40+$ & $189(10.6)$ & Unknown & NA & Saturday & $205(11.5)$ \\
\hline & & & & & & Sunday & $97(5.4)$ \\
\hline
\end{tabular}




\begin{tabular}{|c|c|c|c|c|c|c|c|}
\hline Gender & Service & Age group & Frequency (\%) & Ethnicity & Frequency (\%) & Weekday of attendance & Frequency (\%) \\
\hline & \multirow{7}{*}{$\begin{array}{l}\text { Chlamydia treatment } \\
(\mathrm{n}=206)\end{array}$} & $13-15$ & - & White/White British & 76 (36.9) & Monday & $25(12.1)$ \\
\hline & & $16-19$ & $23(11.2)$ & Asian/Asian British & $16(7.8)$ & Tuesday & $30(14.6)$ \\
\hline & & $20-24$ & $80(38.8)$ & Black/Black British & $42(20.4)$ & Wednesday & $30(14.6)$ \\
\hline & & $25-29$ & $54(26.2)$ & Mixed/Multiple ethnic groups & $18(8.7)$ & Thursday & $32(15.5)$ \\
\hline & & $30-39$ & $35(17.0)$ & Other ethnic groups & $4(1.9)$ & Friday & $41(19.9)$ \\
\hline & & $40+$ & $14(6.8)$ & Unknown & $50(24.3)$ & Saturday & $40(19.4)$ \\
\hline & & & & & & Sunday & $8(3.9)$ \\
\hline
\end{tabular}

*The distribution of age, ethnicity and weekday accessed was not provided for transgender people because the numbers for this group were too little.

NA, not available.

127 and 176 pharmacies between August 2015 and August 2018), compared with other services (oral contraception, contraceptive injection, chlamydia treatment) which were restricted to a limited number of pharmacies (between 18 and 47 pharmacies between August 2015 and August 2018).

Those self-identifying as female comprised the large majority of requests. Those between the ages of 16 and 24 accounted for more than $50 \%$ of requests. Most requests, for which ethnicity data were available, were made by those recorded as White/ White British and Asian/Asian British. Monday was the most common day to present, whereas Saturday and Sunday were the days with lowest attendances. The majority of service requests occurring at the weekend and on Monday, were made by women presenting for emergency contraception.

\section{Comparison with existing literature}

Attendance patterns by gender varied and it was found that emergency contraception, condoms and STI self-sampling kits were most commonly requested on Mondays. It is likely that women requesting emergency contraception are also offered condoms and STI self-sampling kits by pharmacy staff when they attend. This would suggest that the concept of integrated services, where several services are provided in one visit, is working. Males appear to obtain condoms before the weekend, possibly because sexual intercourse is more likely to occur at the weekend. ${ }^{9}$

Our analysis found that pharmacy-based SRHS accessible to both sexes were used less frequently by those self identifying as male than female, which is consistent with previous studies that reported a lower proportion of males attending for STI testing in a community pharmacy setting. ${ }^{6}{ }^{10}$ This could indicate a barrier for male pharmacy-based SRHS access, possibly linked to the high proportion of female support staff in pharmacies. ${ }^{11}$ Males report a preference for having a consultation with a male health provider $^{12}$ and having to approach female staff for SRHS might act as a deterrent. ${ }^{13}$ However, males are generally less likely than females to attend for healthcare ${ }^{14}$ and several studies have shown that males are also less likely than females to access STI testing in other settings, including primary care, ${ }^{15}$ sexual health clinics ${ }^{16}$ and commercial venues. ${ }^{17}$ Males also have a lower uptake of self-sampling based STI testing, ${ }^{18}$ and less frequently order STI kits online $^{1619}$ or return STI kits sent to their homes. ${ }^{20-22}$ This suggests that the reduced use of sexual health services observed in males is not specific to pharmacies and indicates a need for further research to investigate the reasons for this and how best to address it. ${ }^{23}$

We only analysed STI self-sampling kits that were provided through Umbrella pharmacies whereas a recent study analysed the utilisation of Umbrella's clinic-based STI testing and online STI self-sampling kits that were sent to people's homes or collected at the clinic. We found that only one transgender person was provided with an STI kit through the pharmacy over 3 years; in contrast, the online testing based study found 14 transgender people pre-ordered an STI kit to their home or to a clinic, and 26 transgender people were provided with STI screening at the clinic within a 6 -month period. ${ }^{16}$ A recent study found that community pharmacists felt that discrimination and lack of provider knowledge were identified as barriers to pharmacies for transgender people, and the low uptake of services by transgender people may support this finding. ${ }^{24}$ However, it is also possible that transgender people may have been incorrectly recorded as female or male and therefore not have been captured in our data set.

Based on the available ethnicity data, ethnic groups using SRHS in pharmacies were represented approximately in proportion to their prevalence in the local population ${ }^{25}$-White/White British (census $57.9 \%$ cf. study population 43.4\%), Asian/Asian British (census $23.7 \%$ cf. study population 23.1\%), Black/Black British (census $7.2 \%$ cf. study population 15.1\%), Mixed/Mixed British (census $4.4 \%$ cf. study population $2.0 \%$ ) and other ethnic groups (census $6.7 \%$ cf. study population 5.8\%). Black/Black British appeared to be over-represented in comparison with the local population, suggesting that pharmacies may reach those associated with potentially poor sexual health outcomes. ${ }^{26}$ However, available data identified the number of service requests rather than the number of individual patients so this should be interpreted with caution.

Young people are particularly vulnerable to poor sexual health outcomes. ${ }^{27}$ Our data showed that people in the age group from 16 to 24 years old made up the majority of service requests and indicates that pharmacies have the potential to reach young people who are in high need for SRHS. Further, a higher proportion of those attending for STI screening were aged 16-24 in pharmacies compared with sexual health clinic attendees $(3365 / 5530(62.9 \%)) \quad$ cf. $9654 / 19193 \quad(50 \%)))^{16}$ suggesting that pharmacy-based STI testing is acceptable to this demographic.

In line with other studies, we found that the total number of emergency contraception requests was highest on Mondays and lowest on Sundays. ${ }^{28} 29$ This may reflect difficulties in accessing pharmacies on Sundays, as a result of variable pharmacy hours, closure or unavailability of trained staff. According to data provided by Umbrella, the majority of Umbrella pharmacies $(76.7 \%, 122 / 159)$ are closed on Sunday, suggesting that limited Sunday access was the reason for the low uptake of services. However, retrospective data on opening times are not available and these opening times may have differed in the past. Limited availability is a concern because emergency contraception is more effective when taken earlier after unprotected $\operatorname{sex}^{28} 29$ suggesting that more research is required to explore the impact of limiting access. 


\section{Strengths and limitations}

Although understanding healthcare utilisation is crucial to identify barriers to access, previous literature on the utilisation of pharmacy-based sexual health services is scarce and limited to the delivery of single sexual health services. This is the first study evaluating SRHS data collected over a prolonged period of time. A limitation of the study is that the uptake of services over time could not be analysed because the date of attendance was unavailable from the service provider. Another limitation of this study is that the findings are limited to a single health provider in Birmingham and relied on routinely collected data which limited the possible analyses. Missing data meant that the utilisation of STI self-sampling kits could not be described in terms of ethnicity and the lack of a reliable patient ID number prevented analysis at a patient level. Furthermore, transgender people might not have been identified as they may be recorded as female or male rather than transgender.

Our findings suggest that Umbrella's novel pharmacy service, which encompasses more than 120 pharmacies serving a population over 1 million people and including attendees from a wide range of ethnic backgrounds, can provide useful background information to those planning and delivering pharmacy services elsewhere.

\section{Implications for practice and future research}

Research into the reasons for variation in service uptake according to different days of the week would be useful to better understand why this occurs. This might include analysis of pharmacies' opening times and the time taken to access emergency contraception after intercourse.

Barriers to males accessing sexual health services and black people accessing pharmacy-based sexual health services also warrants further investigation. However, a main recommendation of this study is for sexual health providers to design systems which optimise efficient data collection to enable rigorous and comprehensive analysis. Data linkage to enable anonymised identification of sexual health service attendees across integrated sexual health services would allow an analysis of utilisation at the patient level and assist future evaluations. Further, accounting for both gender and sex in data collection would improve the quality analysis ${ }^{30}$ and should also be considered. Finally, research on whether the type of person using pharmacy-based SRHS reflects how and where those services were advertised is needed to understand the effectiveness of reaching certain demographics by advertisement.

\section{Key messages}

- This retrospective study is the first to describe the utilisation of a large range of pharmacy-based SRHS.

- Further exploration of the impact of limited Sunday access is needed.

- Barriers to males accessing sexual health services and barriers to Black/Black British people using pharmacy-based services need to be explored.

- Data collection that allows comprehensive and rigorous analysis of the utilisation of pharmacy-based SRHS should be implemented by sexual health providers.

\section{Handling editor Jason J Ong}

Twitter Julia Gauly @julia_gauly

Acknowledgements The authors would like to thank the Health Informatics Team at UHB for anonymising and providing the data sets. The authors also appreciate the support of the Umbrella team who provided valuable information on the data set.
Funding This study was funded by the University Hospitals Birmingham NHS Foundation Trust.

Competing interests None declared.

Patient consent for publication Not required.

Ethics approval NHS REC and HRA approval (Rec Reference: 18/SC/0511), in addition to local NHS Trust approval (Ref number: RKK6366), was obtained prior to the study commencing.

Provenance and peer review Not commissioned; externally peer reviewed.

Data availability statement All data relevant to the study are included in the article or uploaded as online supplementary information. The anonymised data analysed in the current study are owned by Umbrella which is part of the University Hospitals Birmingham NHS Foundation Trust (funder of this study). Umbrella is licensed to use the data for any legitimate purpose in anonymised form.

Open access This is an open access article distributed in accordance with the Creative Commons Attribution Non Commercial (CC BY-NC 4.0) license, which permits others to distribute, remix, adapt, build upon this work non-commercially, and license their derivative works on different terms, provided the original work is properly cited, appropriate credit is given, any changes made indicated, and the use is non-commercial. See: http://creativecommons.org/licenses/by-nc/4.0/.

\section{ORCID iD}

Julia Gauly http://orcid.org/0000-0002-7835-0882

\section{REFERENCES}

1 Hindi AMK, Schafheutle El, Jacobs S. Patient and public perspectives of community pharmacies in the United Kingdom: a systematic review. Health Expect 2018;21:409-28

2 Boog K, Chen ZE, Cameron S. Sexual and reproductive healthcare providers' opinions on expansion of pharmacy-led provision of contraception. BMJ Sex Reprod Health 2019;45:183-9.

3 Public Health England. Sexual health, reproductive health and HIV: a review of commissioning, 2017: 1-117. https://www.gov.uk/

4 Schoevers MA, Loeffen MJ, van den Muijsenbergh ME, et al. Health care utilisation and problems in accessing health care of female undocumented immigrants in the Netherlands. Int J Public Health 2010:55:421-8.

5 Parsons J, Adams C, Aziz N, et al. Evaluation of a community pharmacy delivered oral contraception service. J Fam Plann Reprod Health Care 2013;39:97-101.

6 Anderson C, Thornley T. A pharmacy-based private Chlamydia screening programme: results from the first 2 years of screening and treatment. Int J Clin Pharm 2011;33:88-91.

7 Umbrella [Internet], 2020. Available: https://umbrellahealth.co.uk/

8 South Gloucestershire Health and Wellbeing Board. Pharmaceutical Needs Assessment, 2015. Available: http://psnc.org.uk/avon-lpc/wp-content/uploads/sites/ 23/2013/06/South-Glos-Final-PNA-For-Publication.pdf

9 Tan PL. Too stressed for sex? Low sex marriages in Singapore. 2020, 2020.

10 Debattista J, Hayes M, Marshall P, et al. A trial of pharmacy-based testing for Chlamydia trachomatis using postal specimen kits. J Pharm Pract Res 2017;47:41-6.

11 Schafheutle El, Samuels T, Hassell K. Support staff in community pharmacy: who are they and what do they want? Int J Pharm Pract 2008;16:57-63.

12 Delgado A, López-Fernández L-A, Luna JdeD, et al. The role of expectations in preferences of patients for a female or male general practitioner. Patient Educ Couns 2011;82:49-57.

13 Ryder H, Aspden T, Sheridan J. The Hawke's Bay Condom Card Scheme: a qualitative study of the views of service providers on increased, discreet access for youth to free condoms. Int J Pharm Pract 2015;2001:381-9.

14 Galdas PM, Cheater F, Marshall P. Men and health help-seeking behaviour: literature review. J Adv Nurs 2005:49:616-23.

15 Kong FYS, Guy RJ, Hocking JS, et al. Australian general practitioner Chlamydia testing rates among young people. Med J Aust 2011;194:249-52.

16 Banerjee P, Thorley N, Radcliffe K. A service evaluation comparing home-based testing to clinic-based testing for Chlamydia and gonorrhoea in Birmingham and Solihull. Int STD AIDS 2018:29:974-9.

17 Williamson LM, Scott G, Carrick-Anderson K, et al. Chlamydia trachomatis testing among 13-25-year-olds in non-genitourinary medicine settings. BMJ Sex Reprod Heal 2007;33:177-82

18 Paudyal P, Llewellyn C, Lau J, et al. Obtaining self-samples to diagnose curable sexually transmitted infections: a systematic review of patients' experiences. PLoS One 2015:10:e0124310-22.

19 Novak DP, Karlsson RB. Simplifying Chlamydia testing: an innovative Chlamydia trachomatis testing approach using the Internet and a home sampling strategy: population based study. Sex Transm Infect 2006;82:142-7.

20 Götz HM, Veldhuijzen IK, van Bergen JEAM, et al. Acceptability and consequences of screening for Chlamydia trachomatis by home-based urine testing. Sex Transm Dis 2005;32:557-62. 
21 Goulet V, de Barbeyrac B, Raherison S, et al. Prevalence of Chlamydia trachomatis: results from the first national population-based survey in France. Sex Transm Infect 2010;86:263-70.

22 Macleod J, Salisbury C, Low N, et al. Coverage and uptake of systematic postal screening for genital Chlamydia trachomatis and prevalence of infection in the United Kingdom general population: cross sectional study. BMJ 2005;330:940.

23 Kalmuss D, Tatum C. Patterns of men's use of sexual and reproductive health services. Perspect Sex Reprod Health 2007;39:74-81.

24 Leach C, Layson-Wolf C. Survey of community pharmacy residents' perceptions of transgender health management. J Am Pharm Assoc 2016;56:441-5.

25 Birmingham City Council. 2011 Census quick profile for Birmingham [Internet], 2011. Available: https://www.birmingham.gov.uk/downloads/file/9849/2011_census_ quick_profile_for_birmingham
26 Fenton KA. Strategies for improving sexual health in ethnic minorities. Curr Opin Infect Dis 2001;14:63-9.

27 Slater C, Robinson AJ. Sexual health in adolescents. Clin Dermatol 2014;32:189-95.

28 Killick SR, Irving G. A national study examining the effect of making emergency hormonal contraception available without prescription. Hum Reprod 2004;19:553-7.

29 Mantzourani E, Hodson K, Evans A, et al. A 5-year evaluation of the emergency contraception enhanced community pharmacy service provided in Wales. BMJ Sex Reprod Health 2019. doi:10.1136/bmjsrh-2018-200236. [Epub ahead of print: 08 Aug 2019].

30 Sharman Z, Johnson J. Towards the inclusion of gender and sex in health research and funding: an institutional perspective. Soc Sci Med 2012;74:1812-6. 